\title{
Climate Change may Reduce Annual Temperature-Dependent Mortality in Subarctic: A Case Study of Archangelsk, Russian Federation
}

\author{
Dmitry Shaposhnikov (Corresponding author) \\ Institute of Economic Forecasting, Russian Academy of Sciences \\ 47 Nakhimovsky Prospect, Moscow 117418, Russia \\ Tel: 7-926-598-2228 E-mail: dshap@newmail.ru \\ Boris Revich \\ Institute of Economic Forecasting, Russian Academy of Sciences \\ 47 Nakhimovsky Prospect, Moscow 117418, Russia \\ Tel: 7-495-129-1800 E-mail: brevich@yandex.ru \\ Valentin Meleshko \\ Voeikov Main Geophysical Observatory \\ Russian Federal Service for Hydrometeorology and Environmental Monitoring \\ 7 Karbysheva Street, Saint-Petersburg, 194021, Russia \\ Tel: 7-812-297-8661Ｅ-mail: meleshko@main.mgo.rssi.ru \\ Veronika Govorkova \\ Voeikov Main Geophysical Observatory \\ Russian Federal Service for Hydrometeorology and Environmental Monitoring \\ 7 Karbysheva Street, Saint-Petersburg, 194021, Russia \\ Tel: 7-812-297-8661Ｅ-mail: veronika@main.mgo.rssi.ru \\ Tatyana Pavlova \\ Voeikov Main Geophysical Observatory \\ Russian Federal Service for Hydrometeorology and Environmental Monitoring \\ 7 Karbysheva Street, Saint-Petersburg, 194021, Russia \\ Tel: 7-812-297-8661 E-mail: pavlova@main.mgo.rssi.ru
}

Received: September 29, 2011

Accepted: October 23, 2011

Published: December 1, 2011

doi: $10.5539 /$ enrr.v1n1p75

URL: http://dx.doi.org/10.5539/enrr.v1n1p75

This publication has been developed within the World Health Organization and the German Federal Ministry for the Environment, Nature Conservation and Nuclear Safety project on protecting health from climate change in Europe, coordinated by Dr B. Menne and Dr J. Nurse, WHO Regional Office for Europe. We are grateful for the financial support received from Germany. The authors affiliated with Voeikov Main Geophysical Observatory were partly supported by the Russian Foundation for Basic Research. 


\begin{abstract}
The impact of increasing temperatures on age- and cause-specific mortality has been examined for the city of Archangelsk in Russian Subarctic, paying equal attention to heat and cold stress. Projections of future daily temperatures and temperature waves were made for IPCC A2 $\mathrm{CO}_{2}$ emission scenario using regional downscaling of the selected ensemble of nine General Circulation Models. Relative changes in annual mortality attributed to climate warming were negative for five studied causes of mortality: all external causes, all non-accidental causes, coronary, cerebrovascular and respiratory diseases in two age groups: $30-64$ and $\geq 65$ years. For most causes, the estimated relative changes were significant at $95 \%$ level. The benefits of reduced cold-related mortality will most likely outweigh the negative impacts of higher heat-related mortality. The relative input of heat and cold waves in the resultant change in annual mortality is several times smaller than the input of smooth temperature-mortality relationships.
\end{abstract}

Keywords: Climate models, Extreme weather events, Global warming, Population health, Time-series models

\title{
1. Introduction
}

We depart from an assumption of the IPCC Fourth Assessment Report (AR4) that anthropogenic emissions of greenhouse gases are partly responsible for changing climate of our planet (Solomon et al., 2007). The attempts of the scientific community to quantify the projected changes in global and regional climate have led to development of atmosphere-ocean coupled general circulation models (AOGCM), on one hand, and future scenarios of emissions of greenhouse gases (GHG) and aerosols, on the other hand. Using these scenarios as inputs to AOGCMs, the degree of anthropogenic influence on climate in the $21^{\text {st }}$ century can be in principle estimated, which is important for public health concerns as there is mounting evidence that climatic variables may significantly affect public health through a variety of causative links, or pathways.

Some of the direct health impacts of climate change can be quantified using statistical relationships between climatic variables and public health endpoints, most importantly, morbidity and mortality rates. For a number of reasons, the relationships between morbidity and weather are generally weaker than those between mortality and weather (Linares \& Diaz, 2008; Michelozzi et al., 2005; Jones et al., 1982).

The decision to conduct a site-specific case study of direct impacts of rising near-surface temperatures on mortality was taken in 2010, when several working groups were formed to implement the project "Climate change and adaptation assessment in the North of the Russian Federation", implemented jointly in the Archangelsk region by the World Health Organization and the Russian Ministry of Health and Social Development in cooperation with the Northern State Medical University, Archangelsk regional authorities, the Federal Service for Hydrometeorology and Environmental Monitoring, and Russian Academy of Medical Sciences. This study had become a task for one of the workgroups. The city of Archangelsk, population 369000 (1999), is one of the largest in Russian Subarctic region. It is situated near the coast of the White Sea, about 220 $\mathrm{km}$ south from the Arctic Circle. As most climate models predict that circumpolar regions will experience greater climatic changes than global averages, the researchers take increasing interest in this region. We hope that the results of such health impact assessment can be directly relevant for other subarctic regions in Europe, Canada and the US.

An ensemble of AOGCMs was selected for this project to produce a reliable regional-level forecast of daily average temperatures, so the epidemiological input was also focused on the relationships between daily temperature and mortality. The studies of temperature/mortality relationships may be subdivided into time-series regression analyses of large arrays of consecutive daily data, and analyses of discrete weather events temperature waves. Regression analysis is used to establish the overall shape of temperature-mortality curve in the whole range of temperature variation but the extreme temperatures (where such curves usually lose statistical significance because of small number of observations). Moreover, there is evidence that excess mortality during temperature extremes can be greater than predicted by regression models (Hajat, Kovats, Atkinson \& Haines, 2002). For this reason, discrete weather events, such as heat waves and cold spells, are usually excluded from time-series regression analysis of large datasets and analyzed separately.

The goal of the current study was to estimate potential changes in mortality rates in Archangelsk city between the future period 2041-2060 and historic period 1999-2008 via both mechanisms, or pathways: (1) combining temperature-mortality curves with daily temperature anomalies and (2) combining the relative risks of mortality during heat waves and cold spells with the expected changes in the distributions of these extreme weather events. Having achieved this goal, we were then able to weight relative inputs of these mechanisms. As shown on Figure 1, Mechanism I explores evolution of daily mortality due to changes in the distribution of daily mean temperatures, while Mechanism II accounts for changes in mortality induced by changing parameters of 
temperature waves. Special attention was paid to the analysis of two leading types of uncertainty: inter-model variation in the selected ensemble of AOGCMs and statistical noise due to small absolute numbers of daily deaths.

\section{Methods and Materials}

\subsection{Data}

IPCC AR4 uses 1980-1999 as the baseline period for climate simulations, but the daily mortality data for Archangelsk in ICD-10 format were available from Russian Federal Statistical Service (Rosstat) only for the period between 1999 and 2008, so this period was used to obtain the basic temperature-mortality relationships for this study. We believe that these relationships reflect fundamental adaptation properties of local populations and cannot change noticeably over a few years, unless there are massive migrations. Mean daily temperatures for this study were calculated on the basis of the 3-hour air temperature data recorded by Archangelsk weather station, which belongs to the network of Federal Service for Hydrometeorology and Environmental Monitoring (Roshydromet).

Figure 1 illustrates our approach to estimating the effects of climate change on mortality. Cause- and age-specific mortality was linked to the projected changes in climate between the future period (2041-2060) and the baseline period (1980-1999), which approximated current conditions. We developed a database of daily mortality counts, subdivided into ten categories: by two age groups and five causes of death (Table 1). The two selected age groups represented able-bodied population excluding young people (30-64 years of age) and retired people ( $\geq 65$ years of age). The number of deaths in age group below 30 years was too small to analyze. The selected causes of death reflected current understanding of climate-dependent causes: we separately analyzed mortality from all external causes and all non-accidental deaths; within the latter we specifically studied deaths from ischemic or coronary heart disease, brain strokes and cerebrovascular diseases, and respiratory diseases. Thus, all types of analysis were carried out for the ten selected indicators of mortality, which substantially increased the level of detail and utility of the results for the decision makers. It was one of the few studies which focused on the external causes, although we did not make any inferences as to which of these were particularly responsible for the observed climate-induced relationships.

\subsection{Modeling temperature-mortality relationships}

Generalized linear model (1) was used to explain variations in expected daily mortality $E(M)$ due to variations in daily weather $(W)$ and temporal confounding, which in turn was the sum of day-of-week regularities $(D O W)$ and slow fluctuations in mortality $S$ (time), as follows:

$$
\log E(M)=W+D O W+S(\text { time })
$$

$D O W$ was calculated as a set of seven constants, representing mean mortality for each of the seven days of the week. Preliminary tests showed that for six out of ten indicators of mortality the differences between these mean values were statistically significant. The function S(time) reproduced both secular trends and seasonal quasi-periodicity and was modeled as a non-parametric function of time with the desired degree of smoothness, as described in (Revich \& Shaposhnikov, 2010a).

Function $W$ may depend upon several meteorological variables (air temperature, barometric pressure, humidity, cloud cover, wind) and even geomagnetic activity. However, the analysis of literature suggested that ambient temperature was the most important health predictor among these, in terms of documented evidence and relative magnitude of induced health effects (Kalkstein \& Davis, 1989; Revich, Shaposhnikov, Gurfinkel, Mitrofanova \& Naumova, 2011). And, of course, near-surface temperature remains the most thoroughly discussed climatic variable in the projections of global warming. For the purposes of the present study, function $W$ depended only upon daily mean temperature and was modeled separately for heat and for cold as described below.

Firstly, the temperature which corresponded to minimum mortality was roughly determined by plotting unprocessed mortality data against same-day temperature, as described in (Revich \& Shaposhnikov, 2008). The minimum of temperature-mortality curve was established for each mortality indicator, except respiratory causes, for which mortality monotonously diminished within the whole range of daily temperatures, and the break-down temperature was defined as the point of a sharp downward kink of mortality, which was clearly seen on the graph for age group 30-64 (Figure 2). For some indicators of mortality, we observed a plateau instead of a single point of minimum on the plot. In this case, the break-down temperature was defined as the upper temperature threshold $\psi$ where mortality began to increase noticeably.

Secondly, we explored the delayed effects of cold stress, finding the time lag $K_{\text {cold }}$ which maximized the statistical significance of the log-relative rates $\alpha_{k}$ under a univariate linear regression model (2): 


$$
\mathrm{W}=\alpha_{k} T_{k} \theta\left(\psi-T_{k}\right)
$$

where $T_{k}$ denotes " $k$-delayed" temperature, taken with either alternative time lag $k$ which could vary between 0 and 12 days prior to the day of death, or cumulative time lag, representing the arithmetic mean of the temperatures summed over the period of up to 4 days, including the day of death: $k=0-1 ; 0-2 ; 0-3$ and $0-4 ; \theta$ is a standard notation of theta-function which indicates that only 'cold' days with temperatures below $\psi$ are included in the segmented model.

Thirdly, using the established time lag, we varied the temperature threshold $\psi$ downward by small decrements to establish the lower temperature threshold $\psi_{\text {coldl }}$, which maximized statistical significance of regression coefficient $\alpha_{K_{-} \text {cold }}$. The temperature-mortality relationship between temperatures $\psi_{\text {coldl }}$ and $\psi$ was then assumed to be a horizontal plateau.

Then, a possible non-linearity of temperature-mortality relationship was investigated, by using either linear threshold or parabolic parameterization of temperature-mortality relationship at the temperature interval between $T_{\min }$ and $\psi_{\text {cold }}$, where $T_{\min }$ was the extreme cold cut-off point, below which the temperature-mortality relationship rapidly lost its statistical significance due to a small number of observations. Under a two-piece linear piecewise model, the kink temperature was estimated simultaneously with the model parameters, as described in (Revich et al., 2011). The choice between linear threshold or parabolic approximations was based on statistical significance of the regression coefficients, overall goodness of fit and analysis of the residuals. This approach grasped the essential concavity of temperature-mortality relationship, at the same time providing simple analytical expressions for its slope factors, which could not be attained using temperature spline functions.

Finally, the magnitude of harvesting effect, or short-term displacement of mortality, was estimated from a linear model with distributed lags:

$$
W=\Theta\left(\psi_{\text {cold } 1}-T_{K_{-} \text {cold }}\right) \sum_{k=K_{-} \text {cold }}^{50} \alpha_{k} T_{k}
$$

Despite the strong correlation of the regressors $T_{k}$ in (3), preliminary trials showed that the row

$$
\sum_{k=K_{-} \text {cold }} \alpha_{k}
$$

satisfactorily converged by the $50^{\text {th }}$ day for all indicators of mortality. Since the temperature threshold was estimated exogenously as described in steps 2 and 3, this model could accommodate cumulative time lags. For example, if $K_{\text {cold }}=0-4$, then $\sum_{k=K \text { cold }} \alpha_{k}=\alpha_{0-4}+\alpha_{5}+\ldots$ Thus, model (3) was a simplified version of the one used

by Muggeo and Hajat (2009), where the temperature thresholds were determined endogenously. While the acute effect of temperature stress was characterized by $\alpha_{K_{-} \text {cold }}$, estimated under model (2), the long-term effect was characterized by the sum of the regression coefficients $\sum_{k=K_{-} \text {cold }}^{50} \alpha_{k}$, calculated under model (3). We defined the "long-term multiplier" as their ratio, ${ }_{L T M_{\text {cold }}}=\frac{\sum_{\alpha_{K_{-} \text {cold }}}}{\alpha_{k}}$, which was then applied as a conversion factor to estimate long-term effect of temperature stress on mortality, even if the acute effect was estimated from the quadratic approximation of temperature-mortality relationship. This way we avoided overestimation of temperature effects for those indicators of mortality, where the short-term displacement of deaths was significant. Note that for some indicators of mortality LTM was actually greater than 1 (Table 3).

The same succession of steps was applied then to the 'high' temperature segment $(T>\psi)$, and produced the estimates of the log-relative rates for heat stress $\beta_{k}, K_{\text {heat }}, \psi_{\text {heat }}, T_{\max }$, possible concavity of mortality response to heat, and $L T M_{\text {heat }}$.

\subsection{Definition of temperature waves}

An essential part of this study was to estimate relative changes in annual mortality rates due to the expected changes in the distribution of temperature waves between the historic and future periods. These distributions are characterized by amplitude, duration, and frequency of temperature waves. Twenty-year periods contain enough waves to average out random variations in the amplitudes of waves, so that the issue of amplitude was not considered as such. On the other hand, the number of waves during the period for which daily mortality data was available (1999-2008) was not sufficient to regress health impact against wave duration, and we simply pooled all temperature waves in two ensembles: "short" (between 5 and 7 days) and "long" waves ( $\geq 8$ days). The waves shorter than 5 days were not considered because the applied criterion for hypothesis testing was not sensitive enough to reject the 'no health impact' hypothesis due to large relative standard error of daily deaths (Table 1). Besides, previous research showed that the effect of sustained heat (as opposed to single hot days) was apparent 
only after 4 consecutive heat-wave days (Gasparini \& Armstrong, 2011). We required that during all days of a heat wave daily mean temperatures should exceed heat threshold, and during cold spell the daily mean temperatures should be below the cold threshold, which were set at the $97^{\text {th }}$ and the $3^{\text {rd }}$ centiles of the 'historic' distribution of daily mean temperatures.

\subsection{Estimating excess mortality during temperature waves}

For the purposes of future health projections, we needed estimates of cumulative impacts of the ensembles of temperature waves during the baseline and future periods. This is why the significance of health impact of each individual wave was not tested. Instead, null hypotheses were tested for six ensembles: short, long and a pooled sample of all heat waves with duration $\geq 5$ days, and the same for cold. For each ensemble, we normalized the originally strongly skewed Poisson distributions of daily mortality rates $M_{t}$ and used dispersion analysis of independent samples, drawn from this distribution. Since most waves were observed on different years, their health effects were assumed independent from each other. To meet the independency assumption, we excluded from the sample the second wave of each pair, if such pairs of waves were separated only by a few days.

The normalization was attained by moving averaging: $\bar{M}_{t}=\frac{\sum_{i=0}^{N-1} M_{t+i}}{N}$, where $N$ is average duration of waves in the ensemble. We checked that at $N \geq 6$ the distribution $\left\{\overline{M_{t}}\right\}$ became sufficiently close to normal. This was another reason for exclusion of very short waves. Then, the relative increase in mortality during the wave $j$ could be approximated by the ratio $R R_{0 j}=\frac{\overline{M_{0 j}}}{S_{0 j}}$, where $\overline{M_{0 j}}$ is taken on the first day of wave $j$, and $S$ denotes seasonal mortality smooth function, obtained by the same algorithm as in Eq. (1) but without log transformation of death rates; the index ' 0 ' reminds of the zero time lag between temperature wave and mortality response. We then assumed that the time lag $l$ could vary between zero and $L=2$ days for heat waves and between zero and $L=14$ days for cold waves, and for each wave chose the maximum of $l$-delayed health effects (Revich $\&$ Shaposhnikov, 2010b; Kysely, Pokorna, Kyncl \& Kriz, 2009):

$$
R R_{j}=\max _{l=0, \ldots, L} R R_{l j}
$$

Although this approximation did not differentiate between the lengths of individual waves in the ensemble, as if they all lasted for $N$ days, it allowed us to consider an independent sample of $n R R$ values ( $n$ is the number of waves in the ensemble) and use standard dispersion analysis for hypothesis testing. The value of Student $t$-test is:

$$
t=\frac{\left.\overline{(R R}-\operatorname{mean}\left\{R R_{L}\right\}\right) \sqrt{n}}{\sigma\left\{R R_{L}\right\}}
$$

where $\overline{R R}$ is the sample mean (approximating average relative mortality risk for the ensemble of waves); mean $\left\{R R_{L}\right\}$ and $\sigma\left\{R R_{L}\right\}$ are the mean and standard deviation of the parent distribution of relative risks, calculated with Eq. (4) for all days of the study period. Note that $\operatorname{mean}\left\{R R_{L}\right\}$ is greater than 1 , because $\left\{R R_{L}\right\}$ is the population of maximums chosen from $L$ relative risks within the moving window, and relative increases in mortality during temperature waves need to be corrected to avoid overestimation of risks due to mere chance:

\subsection{Projections of future climate}

$$
\overline{R R}_{\text {corr }}=\frac{\overline{R R}}{\text { mean }\left\{R R_{L}\right\}} \text {. }
$$

Preliminary trials of more than 20 comparable AOGCMs provided the basis for selection of nine models (listed in Table 2) which showed the best results reproducing current climate during the IPCC baseline period (Russian Federal Service for Hydrometeorology and Environmental Monitoring, 2008). These nine models constituted a multi-model ensemble, used for regional climate projections, where each AOGCM was represented by a single simulation of daily ground-level temperatures in the nodes of a regular $2.5^{\circ} \times 2.5^{\circ}$ grid. The results of these simulations were then averaged out so that the principal source of uncertainty stemmed from inter-model differences, rather than intra-model variability (Katsov \& Meleshko, 2004). Such 'multimodel' approach has been extensively used by IPCC WG1 for assessment of future climate projections, despite the ongoing debates about the rationale for model choices (Knutti, Furrer, Tebaldi, Cermak \& Meehl, 2010) Regional climate projections for this study were obtained for the three IPCC emission scenarios: A1B, A2 и B1 (Nakićenović et al., 2000). Model calculations showed that the differences between them were still negligible by the middle of this 
century; they constituted only a small fraction of inter-model variations, typically less than $10 \%$. This is why we chose to present in this paper only the projections for A2 scenario, as the most "pessimistic", in terms of greenhouse gas emissions and population growth. In light of large uncertainties, it did not make sense to speculate on inter-scenario differences.

Since we estimated relative changes in mortality in each age group, we did not need any assumptions about the population growth and changing age structure.

2.6 Assessing health impact via Mechanism I: Combining daily temperature anomalies with temperature-mortality curves

As follows from model (1), relative change in daily mortality between future and historic periods is:

$$
\Delta \mathrm{E}(\mathrm{M})=\frac{e^{W_{f}-e^{W_{h}}}}{e^{W_{h}}}
$$

where both future and historic daily weather $W_{f}$ and $W_{h}$ could be estimated from the ensemble of climate models for any given calendar date, averaged over 20 -year projection and baseline periods, respectively. Both sides of Eq. (6) depend upon historic daily temperature, rather than the calendar date, and $W_{f^{-}} W_{h}$ is a function of historic daily temperature $T_{h}$ and the daily temperature anomaly, corresponding to this $T_{h}$ (Figure 3). Since we knew the exact analytical expression of temperature-mortality curve $E(M)$ from the regression model (1), there was no need of linearization of Eq. (6).

To calculate relative change in average annual (or 20-year) mortality, one needs to take the integral of Eq. (6) over the whole range of $T_{h}$, taking in account that transitional temperatures are observed more frequently than extreme temperatures. This can in principle be attained by introducing the probability of observation of any given temperature over the historic period (probability density function). We took an equivalent approach of numerical evaluation, estimating the percentiles $T_{i}, i=0, \ldots, 99$, of 'historic' distribution of daily temperatures. Then, relative change in annual mortality is given by the sum

$$
\Delta E_{\text {annual }}=\frac{\sum_{i=0}^{99} E\left(M_{i}\right) \Delta E\left(M_{i}\right)}{\sum_{i=0}^{99} E\left(M_{i}\right)}
$$

where daily mortality $M_{i}$ corresponds to the temperature in the middle of each temperature interval $\left(T_{i} ; T_{i+1}\right)$. Subsequent calculations showed that this discrete approximation was sufficient to account for the basic properties of temperature-mortality curves.

\subsection{Assessing health impact via Mechanism II: Changes in temperature wave-induced mortality}

The output of climate models was used to estimate changes in both frequency and duration of temperature waves. Each ensemble of waves is responsible for a certain number of additional deaths. To make their impacts commensurable with Mechanism I estimates, one needs to calculate 20-year average relative increments in mortality attributable to each ensemble. Then, the relative change in average 20-year mortality between future and historic periods due to Mechanism II is simply the difference between the 'future' and 'historic' impacts, summed up for the ensembles of short and long temperature waves:

$$
\Delta E_{\text {waves }}=\sum_{\text {short_heat, long_heat, short_cold,long_cold }} \frac{\left(\overline{R R}_{\text {corr }}-1\right) N\left(n_{f}-n_{h}\right)}{365 \times 20}
$$

Making projections, we assumed that only the expected number of waves $n$ in the ensemble changes over time, while the relative risks and the average lengths $N$ of waves in each ensemble did not change. Total relative change in mortality due to climate change is simply the sum of Mechanism I and Mechanism II inputs, estimated from Eq. (7) and Eq. (8).

\section{Results}

\subsection{Temperature-mortality curves}

Table 3 presents the results of statistical analysis of temperature-mortality relationships; and Figure 2 sketches temperature-mortality curves with $95 \%$ confidence bands. Only two out of twenty temperature-mortality relationships (meaning that high and low temperature segments were investigated separately) could not be established at the $95 \%$ level of statistical significance. These were cerebrovascular deaths in age group 30-64 and 
deaths from external causes in age group $\geq 65$ years, both in the high-temperature segment. Well-described in literature U-shaped curves have been established for all causes of mortality except respiratory, for which these curves monotonously descended in the whole range of annual temperatures. The slope factors of these curves (Table 3) were used for mortality projections under Eq. (7).

An important finding of this study concerns the upper temperature thresholds $\psi_{\text {heat }}$ : the difference between internal and external causes was quite marked. If mortality from the selected internal causes (all natural deaths, coronary and cerebrovascular deaths) began to increase at temperatures above $16.6-17.8^{\circ} \mathrm{C}$, then mortality from all external causes increased only above the threshold of $20.1-21.2^{\circ} \mathrm{C}$. The implications of this finding are better seen if these thresholds expressed in percentiles of historic distribution of daily temperatures. Averaging over the respective causes of death and age groups gives approximately $\psi_{\text {heat }}=92 \%$ centile for internal causes and $\psi_{\text {heat }}$ $=97 \%$ centile for external causes. It means that an average year brings about thirty heat stress days for internal causes, and only ten heat stress days for external causes, and this difference was statistically highly significant. This finding indicates that the underlying physiological mechanisms that link temperature and mortality fundamentally differ for the internal and the external causes. The latter may involve psychological or mental distress, associated with extreme temperatures.

\subsection{Health effects of temperature waves}

Based on the $97^{\text {th }}$ and the $3^{\text {rd }}$ centiles of the historic (1980-1999) distribution of daily mean temperatures, the thresholds for heat and cold waves were respectively defined at $+21.0^{\circ} \mathrm{C}$ and $-21.4^{\circ} \mathrm{C}$. Using the definitions provided in Methods section, we identified four short and four long cold waves during the period of 1999-2008 for which daily mortality data was available; their average wavelengths $N$ were 6 and 13 days. Similarly, five short and five long heat waves with average wavelengths 6 and 10 days were identified. Among these, one pair of cold and one pair of heat waves were closely adjacent, which led to exclusion of the second waves of each pair from the respective test samples, and relative mortality risks were ultimately calculated for the ensembles of four short and three long cold waves; five short and four long heat waves. Table 4 summarizes the results of these calculations. The results were quite robust with respect to cold spells while the evidence of mortality increases during heat waves was scarce. Indeed, statistically significant relative risks of mortality during cold waves were established for seven out of ten indicators of mortality, while only two indicators of mortality showed significant increases during heat waves: mortality from cerebrovascular diseases and from all non-accidental causes in age group $\geq 65$. Because we applied symmetrical definitions to cold and heat waves, in terms of wave duration and temperature thresholds based on percentiles, this finding may indicate that local population is more susceptible to extreme cold than to extreme heat. On the other hand, our failure to reject the null hypothesis in most cases could also be explained by small size of local population and small number of heat waves in the test samples. For the purposes of future mortality projections, we assumed zero increases in mortality for those categories where the null hypothesis could not be rejected at $95 \%$ level of significance (in Table 6).

Another important result in Table 4 is the difference between cold and heat with respect to the wave duration. It seems that only long cold waves had pronounced health effects; this is why statistical significance of relative risk estimates for the pooled sample (short plus long cold waves) was generally lower. However, the opposite was true for heat waves. Henceforth, we based our Mechanism II health projections on the results for the ensemble of long cold waves (except for respiratory diseases in age group 30-64) and the ensemble of all heat waves.

\subsection{Temperature and health projections}

The analysis of daily temperature anomalies as a function of $T_{h}$ suggested that this function nearly linearly decreased in the temperature interval between the $3 \%$ centile and $T_{\text {summer }}$ (the mean summer temperature, $+13.5^{\circ} \mathrm{C}$ ), and flattened out at higher temperatures (Figure 3). We fitted the following regression equation to calculate these anomalies within the indicated interval:

$$
\Delta T=T_{f}-T_{h}=2.97-.087 T_{h}, p<.001
$$

Although the approximation showed on Figure 3 adequately reflects the important result of regional climate projections (greater warming in winter than in summer), estimation of uncertainties based on inter-model differences rendered all subsequent projections of changes in heat-induced health effects statistically non-significant, because the lower $95 \% \mathrm{CL}$ of $\Delta T$ equals to zero for all 'heat-stress' temperatures. This finding also implies that the lower $95 \% \mathrm{CL}$ of the number of heat waves in the future period should be equal to that during the baseline period: see Table 5 for the projected changes in the numbers of temperature waves between the baseline and the future periods. 
The estimates of projected changes in average annual mortality between the baseline and the future periods are summarized in Table 6 and Figure 4. The first two columns in Table 6 were calculated using Eq. (7), where we separately summed up all negative terms, which corresponded to the downward segment of temperature-mortality curve, and all positive terms, which corresponded to the ascending segment of this curve. Thus, these two columns account for the effects of cold stress and heat stress. Please note that the resultant change can be statistically significant even though heat stress-induced change is not, if the relative input of heat-induced change in the total is much smaller than that of cold-induced change. Indeed, the analysis of standard errors associated with Eq. (7) and Eq. (8) showed that the resultant change in mortality was statistically significant for six out of ten indicators of mortality, which is an impressive achievement, given the considerable uncertainties associated with the methods developed for this research.

In absolute terms, the resultant changes in average annual mortality due to Mechanism I, summed up for heat and for cold, varied from $-.3 \%$ for total non-accidental mortality in age group 30-64 to $-4.4 \%$ for respiratory mortality in the same age group; while the obtained estimates due to Mechanism II ranged from $+.08 \%$ for cerebrovascular mortality in age group $\geq 65$ to $-.54 \%$ for external causes mortality in age group $30-64$. Two important conclusions can be drawn from Table 6: (1) the resultant changes in mortality due to both mechanisms combined are negative for all indicators; (2) the relative input of Mechanism II in the resultant change is several times smaller than that of Mechanism I, and can be neglected in the first approximation.

Table 6 shows that climate-dependent causes actually include not only causes due to circulatory and respiratory diseases, but, most interestingly, external causes, which have been rarely considered in climatic studies. Moreover, mortality from external causes appears to be even more sensitive to climate change than non-accidental mortality, as the resultant changes in Table 6 demonstrated. For example, the projected change in annual non-accidental deaths by year 2050 in age group 30-64 was $-.59 \%$, while the change in annual accidental deaths in the same age group was $-2.8 \%$.

The results presented in this paper could not support the hypothesis that the senior age group was generally more sensitive to climate change. Table 6 showed that the magnitudes of estimated health responses were not significantly greater for age group $\geq 65$ years. If we take mortality due to diseases of circulatory system (both coronary disease deaths and cerebrovascular disease deaths), it seems that senior people are more sensitive to climate change. However, the opposite was true with respect to deaths from all external causes.

\section{Discussion}

Our intention to utilize only locally available statistical information to establish temperature-mortality response functions proved to be a major limitation of this study, because the mortality data were available only for ten-year period and in many categories of mortality relative mortality risk estimates for heat waves could not be established at $95 \%$ level of significance. This is why a lot of zeroes appear in Table 6. Despite this uncertainty, there is enough evidence that relative input of Mechanism II to the resultant change in mortality should be several times smaller than that of Mechanism I, which is mainly explained by relatively small number of temperature wave days in any 20 -year period. Therefore, we may expect that further attenuation of temperature wave risk estimates cannot reverse the negative sign of the resultant change in annual mortality. Interestingly enough, our conclusion regarding relative inputs of Mechanisms I and II has been recently indirectly confirmed by Gasparini and Armstrong (2011), who concluded that the "added" effect of sustained heat on mortality was several times smaller than the "main" effect of the equivalent number of individual hot days.

The review of current publications suggested that our paper was probably the only one that attempted to give equal consideration to the two mechanisms which linked the projected changes in distributions of daily temperatures and annual mortality rates: the inferences based on smooth temperature-mortality relationships (Mechanism I) and relative increases in mortality during temperature waves (Mechanism II). Although, in this respect, out study is probably unique, its results can still be compared to those of the international studies which involved climate simulations to predict the impacts of global warming on mortality using either mortality-temperature curves or estimating the effects of extreme climatic events.

The projections of variations in annual and seasonal mortality under A2 and B2 greenhouse gas emission scenarios were calculated for three cities in Canada based on site-specific mortality-temperature curves and monthly future temperatures (Doyon, Belanger \& Gosselin, 2008). For example, in Montreal, the largest of the three cities analyzed, the authors reported a $1.5 \%(95 \% \mathrm{CI} 1.0-2.0 \%)$ increase in annual all-age non-accidental mortality because an increase in summer mortality was not balanced by the decrease in mortality during the fall season, while the variations in winter and spring mortality were close to zero and not statistically significant. In other two cities (Quebec and Sagenay) the projected changes in annual mortality were also positive and 
statistically significant. Therefore, the main conclusion of the Canadian research contradicts to that of our paper. There are two probable explanations for this: (1) The influence of deseasonalization. Temperature-mortality curves in Canadian study considerably changed after application of deseasonalization algorithm, based on natural cubic spline functions of time, especially in the region of cold temperatures, where the curves practically flattened out after deseasonalization, and this explained why the decrease in winter mortality was not significant. We did not observe the same effect in our study. While the deseasonalization indeed slightly reduced the slopes of our temperature-mortality curves, its overall effect was quite modest: in the range of $5-10 \%$. (2) The results of mortality projections greatly depended upon monthly temperature anomalies obtained by regionalization of HadCM3 model used in Canada. Unfortunately, these were not reported, but the authors mention that winter temperature anomalies were below the average of the other models, which might also have downscaled the (negative) change in seasonal winter mortality.

A similar, but restricted only to the three summer months, approach was undertaken in New York, where the authors also computed decade-specific monthly temperature anomalies. Based on the exposure-risk coefficient (derived from the gradient of mortality-temperature curve), the authors reported $95 \%$ and $71 \%$ mean increases in heat-related deaths from all non-accidental causes for NYC Metropolitan Area by 2050 under scenarios A2 and B2 and no acclimatization assumption, compared to 1990s (Knowlton et al., 2007). However, they did not report equivalent increases in annual non-accidental mortality. We took their county-specific population and mortality data and calculated these increases as $0.7 \%$ and $0.5 \%$ under A2 and B2 scenarios, respectively. These estimates closely match ours obtained for heat stress-induced change in annual mortality under Mechanisms I and II combined (Table 6): $0.44 \%$ for all non-accidental deaths in age group 30-64 and $0.55 \%$ in age group $\geq 65$.

A Europe-based PESETA study estimated the changes in total mortality around 2080s, using temperature simulation data over 50-km grid resolution across Europe and country-specific mortality-temperature functions (Watkiss, Horrocks, Pye, Searl \& Hunt, 2009; Ciscar at al., 2011). Typical increases in heat-related deaths varied between 1 and $3 \%$ of total annual mortality, while changes in cold-related deaths for most European countries were between -5 and $-1.5 \%$, under "no acclimatization and no adaptation" assumption and A2 emission scenario. The authors concluded that, taking Europe as a whole, the benefits of reduced cold-related mortality would most likely outweigh the negative impacts of higher heat-related mortality, which agrees with the conclusion of our research. Among the limitations of PESETA study the authors mentioned that the effects of heat waves and cold spells were not considered. Because the authors of PESETA project reported changes in total all-age mortality, we had to combine our estimates for heat and cold -related changes under Mechanism I from Table 6 with daily mortality rates from Table 1 for all external and all non-accidental deaths in both age groups (the input of age group $<30$ is negligible) for a meaningful comparison. This arithmetic exercise produced the following estimates of changes in all-age heat- and cold-related deaths in Archangelsk (assuming no changes in age structure): $0.49 \%$ and $-1.6 \%$, which fare well in European context (please note that PESETA results were reported for year 2080, while ours for year 2050, so that our relative changes should be approximately two times smaller).

As was noted in Methods section, future health impacts of heat waves and cold spells are to be considered separately from the effects of daily (or monthly) temperature anomalies. Unfortunately, so far only heat waves have been considered. A recent US-based study (Peng et al., 2011) estimated the changes in the distribution of heat waves between 1981-2000 and 2081-2100 under seven global circulation models (GCM) and three emission scenarios (B1, A1B, A2) and concluded that heat wave-induced mortality from all non-accidental causes in Chicago would grow from 53 deaths/year to 166-2 217 deaths/year, depending upon the model and scenario used, which was equivalent to an increase by factor of 3-41. The authors of Chicago study used similar analytical approach, projecting future heat-wave mortality. Notably, their estimate of relative risk of mortality from all non-accidental causes during an average heat wave $(R R=1.11$ for age group 65-74) was quite close to our estimate $(R R=1.13$ for age group $\geq 65$, Table 4$)$. They emphasized that inter-model variability led to large discrepancy among projections, and avoided publishing a consensus estimate based on synthesis of multiple models. For this reason, their results cannot be compared directly with ours, but our estimate probably agrees with the lower bound of their range (we estimated a $80 \%$ increase in heat wave-induced mortality by 2050 , based on the projected increase in the number of all heat waves in Table 5).

Our analysis of uncertainties associated with heat impact projections also showed that inter-model variation was the dominant source of uncertainly, especially in summer season, as illustrated by Figure 3. There is little doubt that reliability and accuracy of climate models will increase over time. This paper was drafted in the summer of 2010, when an unprecedented heat wave hit Moscow and all European Russia. In Moscow, daily temperatures exceeded the long-term averages by more than $5^{\circ} \mathrm{C}$ for 45 days in July and August. While there are no theoretical grounds to attribute this wave specifically to climate change, the extreme rarity of such a weather event can be 
easily demonstrated by statistical methods. Clearly, no climate models could have predicted such unlikely event during any 20-year time slot.

This paper utilized both standard and innovative statistical methods and proposed a theoretical framework to compute the expected changes in temperature-related mortality directly attributed to regional climate change. Despite the large uncertainties, there is enough weight of evidence that the resultant impact of regional warming on mortality would be beneficial: for all indicators of mortality, the resultant change in mortality was negative, and this result was statistically significant for most indicators. There are at least two reasons for this: (1) climate models predict much greater warming in winter than in summer season, and (2) the U-shaped temperature-mortality curves are fundamentally asymmetrical with respect to annual distribution of daily temperatures: there are much more cold stress days than heat-stress days. This effect was especially pronounced for mortality from all external causes.

\section{Authors' contributions}

B. Revich initiated and participated in the design of the study, and compiled the data. D. Shaposhnikov participated in the design of the study, performed the statistical analysis and drafted the manuscript. V. Meleshko supervised the climate modeling. V. Govorkova and T. Pavlova supplied the climate models projection data and performed climate change estimation for the region of study.

\section{Acknowledgements}

The authors highlight personal involvement of Dr. E.D. Yurasova of WHO office in the Russian Federation and Z.L. Varakina of Northern State Medical University who provided organizational support for this project. We acknowledge the international modeling groups for providing their data for analysis, the Program for Climate Model Diagnosis and Intercomparison (PCMDI) for collecting and archiving the model data, the JSC/CLIVAR Working Group on Coupled Modelling (WGCM) and their Coupled Model Intercomparison Project (CMIP) and Climate Simulation Panel for organizing the model data analysis activity, and the IPCC WG1 TSU for technical support. The IPCC Data Archive at Lawrence Livermore National Laboratory is supported by the Office of Science, U.S. Department of Energy.

The content is solely the responsibility of the authors and does not necessarily represent the official views of WHO; no official endorsement should be inferred. The authors declare that they have no competing financial interests.

\section{References}

Ciscar, J. C., Iglesias, A., Feyen, L., Szabó, L., Regemorter, D., Amelunge, B., \& Soria, A. (2011). Physical and economic consequences of climate change in Europe. Proceedings of National Academy of Sciences of USA, 108, 2678-2683. http://dx.doi.org/10.1073/pnas.1011612108

Dessai, S. (2003). Heat stress and mortality in Lisbon Part II. An assessment of the potential impacts of climate change. International Journal of Biometeorology, 48, 37-44. http://dx.doi.org/10.1007/s00484-003-0180-4

Doyon, B., Belanger, D., \& Gosselin, P. (2008). The potential impact of climate change on annual and seasonal mortality for three cities in Quebec, Canada. Internatinal Journal of Health Geographics, 7, 23. http://dx.doi.org/10.1186/1476-072X-7-23

Gasparini, A., \& Armstrong, B. (2011). The impact of heat waves on mortality. Epidemiology, 22, 68-73. http://dx.doi.org/10.1097/EDE.0b013e3181fdcd99

Hajat, S., Kovats, R. S., Atkinson, R. W., \& Haines, A. (2002). Impact of hot temperatures on death in London: a time series approach. Journal of Epidemiology and Community Health, 56, 367-372. http://dx.doi.org/10.1136/jech.56.5.367

Jones, T. S., Liang, A. P., Kilbourne, E. M., Griffin, M. R., Patriarca, P. A., Wassilak, S. G., \& Thacker, S. B. (1982). Morbidity and mortality associated with the July 1980 heat wave in St Louis and Kansas City, Mo. Journal of American Medical Association, 247, 3327-3331.

Kalkstein, L. S., \& Davis, R. E. (1989). Weather and human mortality: an evaluation of demographic and interregional responses in the United States. Annals of the Association of American Geographers, 79, 44-64. http://dx.doi.org/10.1111/j.1467-8306.1989.tb00249.x

Kattsov, V. M., \& Meleshko, V. P. (2004). Comparative assessment of atmosphere-ocean coupled general circulation models used for climate projections. Izvestiya, Atmospheric and Oceanic Physics, 40, 647-658.

Knowlton, K., Lynn, B., Goldberg, R. A., Rosenzweig, C., Hogrefe, C., Rosenthal, J. K., \& Kinney, P. L. (2007). 
Projecting heat-related mortality impacts under a changing climate in the New York City Region. American Journal of Public Health, 97, 2028-2034. http://dx.doi.org/10.2105/AJPH.2006.102947

Knutti, R., Furrer, R., Tebaldi, C., Cermak, J., \& Meehl, G. A. (2010). Challenges in combining projections from multiple climate models. Journal of Climate, 23, 2739-2758. http://dx.doi.org/10.1175/2009JCLI3361.1

Kysely, J., Pokorna, L., Kyncl, J. \& Kriz, B. (2009). Excess cardiovascular mortality associated with cold spells in the Czech Republic. BMC Public Health, 9, 19. http://dx.doi.org/10.1186/1471-2458-9-19

Linares, C., \& Diaz, J. (2008). Impact of high temperatures on hospital admissions: comparative analysis with previous studies about mortality (Madrid). European Journal of Public Health, 18, 317-322. http://dx.doi.org/10.1093/eurpub/ckm108

Michelozzi, P., Accetta, G., Kirchmayer, U., Atkinson, R., Anderson, R., Ballester, F., \& Schindler, C. (2005). Short-term effects of apparent temperature on hospital admissions in European cities: results from the PHEWE projects. Epidemiology, 16(5), S138-S139.

Muggeo, V. M. \& Hajat, S. (2009). Modeling the non-linear multiple-lag effects of ambient temperature on mortality in Santiago and Palermo: a constrained segmented distributed lag approach. Occupational and Environmental Medicine, 66, 584-591. http://dx.doi.org/10.1136/oem.2007.038653

Nakićenović, N., Alcamo, J., Davis, G., de Vries, B., Fenhann, J., Gaffin, S., \& Dadi, Z. (2000). IPCC special report on emission scenarios. Cambridge: Cambridge University Press. [Online] Available: http://www.ipcc.ch/ipccreports/sres/emission/index.htm (September 27, 2011)

Peng, R. D., Bobb, J. F., Tebaldi, C., McDaniel, L., Bell, M. L, \& Dominici, F. (2011). Toward a quantitative estimate of future heat wave mortality under global climate change. Environmental Health Perspectives, 119, 701-706. http://dx.doi.org/10.1289/ehp.1002430

Revich, B. \& Shaposhnikov, D. (2008). Temperature-induced excess mortality in Moscow, Russia. International Journal of Biometeorology, 52, 367-374. http://dx.doi.org/10.1007/s00484-007-0131-6

Revich, B. \& Shaposhnikov, D. (2010a). The effects of particulate and ozone pollution on mortality in Moscow, Russia. Air Quality, Atmosphere and Health, 3, 117-123. http://dx.doi.org/10.1007/s11869-009-0058-7

Revich, B. \& Shaposhnikov, D. (2010b). Climate warming and health effects of extreme temperatures in Yakutsk, East Siberia, Remote and Rural Health, 10, 1338. [Online] Retrieved from http://www.rrh.org.au/publishedarticles/article_print_1338.pdf (September 27, 2011)

Revich, B., Shaposhnikov, D., Gurfinkel, Y., Mitrofanova, T. \& Naumova, E. (2011). The influence of meteorological and geomagnetic factors on acute myocardial infarction and brain stroke in Moscow, Russia. International Journal of Biometeorology, in print.

Russian Federal Service for Hydrometeorology and Environmental Monitoring. (2008). Assessment report on climate change and its impacts in the territory of the Russian Federation, Vol.1, Moscow. Retrieved from http://climate2008.igce.ru/v2008/pdf/resume_ob_eng.pdf (September 27, 2011)

Solomon, S., Quin, D., Manning, M., Chen, Z., Marquis, M., Averyt, K. B., ... Miller H. L. (Eds.). (2007). Climate change 2007: The physical science basis. Contribution of Working Group I to the Fourth Assessment Report of the Intergovernmental Panel on Climate Change. Cambridge: Cambridge University Press, Available from http://www.ipcc.ch/publications_and_data/ar4/wg1/en/contents.html (September 27, 2011)

Watkiss, P., Horrocks, L., Pye, S., Searl, A. \& Hunt, A. (2009) Impacts of climate change in human health in Europe. PESETA-Human health study. EC Joint Research Centre, Institute for Prospective Technological Studies, http://dx.doi.org/10.2791/36116 
Table 1. Overview of indicators of mortality included in the study

\begin{tabular}{|c|c|c|}
\hline Cause of death and age group & Mean daily rate & Standard deviation \\
\hline Ischemic heart disease, 30-64 & 1.4 & 1.2 \\
\hline Ischemic heart disease, $\geq 65$ & 2.1 & 1.5 \\
\hline Cerebrovascular diseases, $30-64$ & 0.62 & 0.82 \\
\hline Cerebrovascular diseases, $\geq 65$ & 2.5 & 1.7 \\
\hline Respiratory diseases, 30-64 & 0.42 & 0.65 \\
\hline Respiratory diseases, $\geq 65$ & 0.21 & 0.48 \\
\hline All non-accidental causes, 30-64 & 4.6 & 2.3 \\
\hline All non-accidental causes, $\geq 65$ & 7.0 & 2.8 \\
\hline All external causes, $30-64$ & 1.7 & 1.3 \\
\hline All external causes, $\geq 65$ & 0.27 & 0.52 \\
\hline
\end{tabular}

Table 2. Atmosphere-ocean coupled general circulation models, included in the ensemble for climate projections

\begin{tabular}{|c|c|c|c|}
\hline Acronym & Year & Institution & Country of origin \\
\hline CGCM3.1 (T47) & 2005 & Canadian Centre for Climate Modelling and Analysis & Canada \\
\hline CNRM-CM3 & 2004 & Centre National de Recherches Météorologiques & France \\
\hline CSIRO-Mk3.0 & 2001 & CSIRO Atmospheric Research & Australia \\
\hline ECHAM5/MPI & 2005 & Max-Planck-Institut für Meteorologie & Germany \\
\hline ECHO-G & 1999 & $\begin{array}{c}\text { Meteorological Institute of the University of Bonn, } \\
\text { Institute of KMA }\end{array}$ & $\begin{array}{c}\text { Germany and } \\
\text { Korea }\end{array}$ \\
\hline GFDL-CM2.0 & 2005 & Geophysical Fluid Dynamics Laboratory & USA \\
\hline IPSL-CM4 & 2005 & $\begin{array}{c}\text { Institut Pierre Simon Laplace des Sciences de } \\
\text { l'Environnement Global (IPSL) }\end{array}$ & France \\
\hline MIROC3.2_(me) & 2004 & Frontier Research Center for Global Change & Japan \\
\hline MRI-GCM2.3.2 & 2003 & Meteorological Research Institute & Japan \\
\hline
\end{tabular}


Table 3. Temperature-mortality relationships, after correction for harvesting

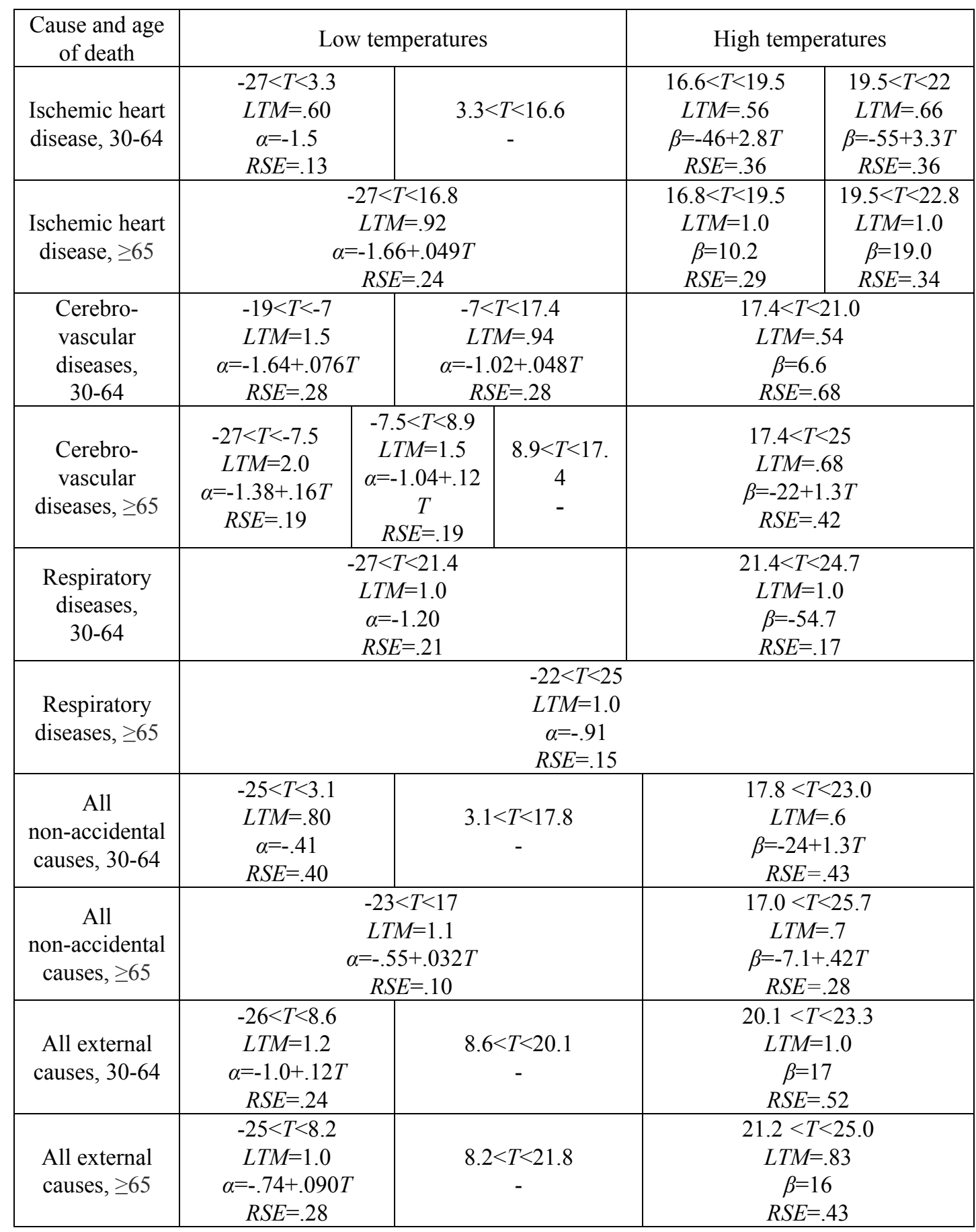

Definition of abbreviations: $L T M=$ Long-term multiplier, or the ratio of long-term to acute effect of temperature change; $\alpha$ and $\beta$ are log-relative rates, or slope factors, expressed as percentage change in mortality per $1^{\circ} \mathrm{C}$ increase in daily mean temperatures $T$ for low and high temperature segments, respectively; $R S E=$ relative standard error of estimate; $R S E \geq .50$ means that the underlying relationship is not statistically significant at $95 \%$ level; symbol "-“" indicates a horizontal plateau. 
Table 4. Relative risks of mortality during the ensembles of temperature waves with $95 \%$ confidence limits (in brackets)

\begin{tabular}{|c|c|c|c|c|c|c|}
\hline & \multicolumn{3}{|c|}{ Cold stress } & \multicolumn{3}{|c|}{ Heat stress } \\
\hline $\begin{array}{l}\text { Cause of death and } \\
\text { age group }\end{array}$ & $\begin{array}{c}\text { Short cold } \\
\text { waves }\end{array}$ & $\begin{array}{l}\text { Long cold } \\
\text { waves }\end{array}$ & $\begin{array}{l}\text { All cold } \\
\text { waves }\end{array}$ & $\begin{array}{l}\text { Short heat } \\
\text { waves }\end{array}$ & $\begin{array}{l}\text { Long heat } \\
\text { waves }\end{array}$ & $\begin{array}{l}\text { All heat } \\
\text { waves }\end{array}$ \\
\hline $\begin{array}{l}\text { Ischemic heart } \\
\text { disease, 30-64 }\end{array}$ & $\begin{array}{c}.93 \\
(.70 ; 1.15)\end{array}$ & $\begin{array}{l}1.44^{*} \\
(1.13 ; \\
1.75)\end{array}$ & $\begin{array}{c}1.18^{*} \\
(1.01 ; 1.35)\end{array}$ & $\begin{array}{c}.85 \\
(.56 ; 1.15)\end{array}$ & $\begin{array}{c}1.03 \\
(.75 ; 1.31)\end{array}$ & $\begin{array}{c}.94 \\
(.74 ; 1.14)\end{array}$ \\
\hline $\begin{array}{l}\text { Ischemic heart } \\
\text { disease, } \geq 65\end{array}$ & $\begin{array}{c}1.06 \\
(.85 ; 1.27)\end{array}$ & $\begin{array}{c}1.32^{*} \\
(1.06 ; \\
1.58)\end{array}$ & $\begin{array}{c}1.22^{*} \\
(1.07 ; 1.36)\end{array}$ & $\begin{array}{c}.85 \\
(.59 ; 1.11)\end{array}$ & $\begin{array}{c}1.02 \\
(.78 ; 1.26)\end{array}$ & $\begin{array}{c}.93 \\
(.76 ; 1.10)\end{array}$ \\
\hline $\begin{array}{l}\text { Cerebrovascular } \\
\text { diseases, 30-64 }\end{array}$ & $\begin{array}{c}.94 \\
(.57 ; 1.31)\end{array}$ & $\begin{array}{c}1.29 \\
(.74 ; 1.83)\end{array}$ & $\begin{array}{c}1.13 \\
(.87 ; 1.39)\end{array}$ & $\begin{array}{c}.99 \\
(.53 ; 1.45)\end{array}$ & $\begin{array}{c}1.01 \\
(.57 ; 1.45)\end{array}$ & $\begin{array}{c}1.01 \\
(.70 ; 1.33)\end{array}$ \\
\hline $\begin{array}{l}\text { Cerebrovascular } \\
\text { diseases, } \geq 65\end{array}$ & $\begin{array}{c}.99 \\
(.80 ; 1.19)\end{array}$ & $\begin{array}{l}1.37^{*} \\
(1.12 ; \\
1.62)\end{array}$ & $\begin{array}{c}1.19^{*} \\
(1.05 ; 1.33)\end{array}$ & $\begin{array}{c}1.36^{*} \\
(1.12 ; 1.59)\end{array}$ & $\begin{array}{c}1.22^{*} \\
(1.00 ; 1.44)\end{array}$ & $\begin{array}{c}1.30^{*} \\
(1.14 ; 1.47)\end{array}$ \\
\hline $\begin{array}{c}\text { Respiratory } \\
\text { diseases, 30-64 }\end{array}$ & $\begin{array}{c}1.09 \\
(.69 ; 1.49)\end{array}$ & $\begin{array}{c}1.41 \\
(.77 ; 2.05)\end{array}$ & $\begin{array}{c}1.31^{*} \\
(1.03 ; 1.60)\end{array}$ & $\begin{array}{c}1.03 \\
(.50 ; 1.56)\end{array}$ & $\begin{array}{c}.73 \\
(.23 ; 1.22)\end{array}$ & $\begin{array}{c}.91 \\
(.55 ; 1.27)\end{array}$ \\
\hline $\begin{array}{c}\text { Respiratory } \\
\text { diseases, } \geq 65\end{array}$ & $\begin{array}{c}.99 \\
(.38 ; 1.60) \\
\end{array}$ & $\begin{array}{c}1.32 \\
(.14 ; 2.50) \\
\end{array}$ & $\begin{array}{c}1.21 \\
(.78 ; 1.65) \\
\end{array}$ & $\begin{array}{c}1.21 \\
(.39 ; 2.03) \\
\end{array}$ & $\begin{array}{c}.89 \\
(.10 ; 1.67) \\
\end{array}$ & $\begin{array}{c}1.09 \\
(.52 ; 1.65) \\
\end{array}$ \\
\hline $\begin{array}{l}\text { All non-accidental } \\
\text { causes, 30-64 }\end{array}$ & $\begin{array}{c}.98 \\
(.83 ; 1.12)\end{array}$ & $\begin{array}{l}1.26^{*} \\
(1.08 ; \\
1.43)\end{array}$ & $\begin{array}{c}1.12^{*} \\
(1.02 ; 1.23)\end{array}$ & $\begin{array}{c}.99 \\
(.81 ; 1.16)\end{array}$ & $\begin{array}{c}1.04 \\
(.88 ; 1.20)\end{array}$ & $\begin{array}{c}1.02 \\
(.90 ; 1.13)\end{array}$ \\
\hline $\begin{array}{l}\text { All non-accidental } \\
\text { causes, } \geq 65\end{array}$ & $\begin{array}{c}1.01 \\
(.87 ; 1.15)\end{array}$ & $\begin{array}{l}1.35^{*} \\
(1.19 ; \\
1.52)\end{array}$ & $\begin{array}{c}1.18^{*} \\
(1.08 ; 1.28)\end{array}$ & $\begin{array}{c}1.11 \\
(.96 ; 1.26)\end{array}$ & $\begin{array}{c}1.14 \\
(.97 ; 1.31)\end{array}$ & $\begin{array}{c}1.13^{*} \\
(1.02 ; 1.24)\end{array}$ \\
\hline $\begin{array}{l}\text { All external } \\
\text { causes, 30-64 }\end{array}$ & $\begin{array}{c}1.10 \\
(.85 ; 1.34)\end{array}$ & $\begin{array}{c}1.47^{*} \\
(1.18 ; \\
1.76)\end{array}$ & $\begin{array}{c}1.29^{*} \\
(1.12 ; 1.46)\end{array}$ & $\begin{array}{c}1.21 \\
(.94 ; 1.48)\end{array}$ & $\begin{array}{c}.99 \\
(.73 ; 1.24)\end{array}$ & $\begin{array}{c}1.16 \\
(.96 ; 1.35)\end{array}$ \\
\hline $\begin{array}{l}\text { All external } \\
\text { causes, } \geq 65\end{array}$ & $\begin{array}{c}1.15 \\
(.72 ; 1.57)\end{array}$ & $\begin{array}{c}.99 \\
(.26 ; 1.72)\end{array}$ & $\begin{array}{c}1.20 \\
(.91 ; 1.50)\end{array}$ & $\begin{array}{c}1.04 \\
(.42 ; 1.67)\end{array}$ & $\begin{array}{c}1.38 \\
(.81 ; 1.95)\end{array}$ & $\begin{array}{c}1.20 \\
(.78 ; 1.63)\end{array}$ \\
\hline
\end{tabular}

${ }^{*}$ Significant at $95 \%$ level.

Table 5. The numbers of temperature waves: actual data for the baseline period 1980-1999 and simulated data for the future period 2041-2060, averaged over the ensemble of nine AOGCMs under A2 emission scenario

\begin{tabular}{|l|c|c|c|c|}
\hline & \multicolumn{2}{|c|}{ Baseline period, $n_{h}$} & \multicolumn{2}{c|}{ Future period, $n_{f}(95 \%$ CL $)$} \\
\hline & $\begin{array}{c}\text { Short waves } \\
(5 \text { to } 7 \text { days })\end{array}$ & $\begin{array}{c}\text { Long waves } \\
(\geq 8 \text { days })\end{array}$ & $\begin{array}{c}\text { Short waves } \\
(5 \text { to } 7 \text { days })\end{array}$ & $\begin{array}{c}\text { Long waves } \\
(\geq 8 \text { days })\end{array}$ \\
\hline Heat waves & 12 & 6 & $18(12 ; 18)^{\mathrm{a}}$ & $15(6 ; 30)$ \\
\hline Cold waves & 8 & 7 & $1.8(0 ; 4)$ & $0.5 \quad(0 ; 4)$ \\
\hline
\end{tabular}

${ }^{a}$ Upper $95 \%$ CL equals to the central estimate in this particular case because as new waves enter the ensemble of short waves, others leave it to join the ensemble of long waves. 
Table 6 . Percentage changes in average annual mortality rates with $95 \%$ confidence limits (in brackets) between the future (2041-2060) and the baseline (1980-1999) periods

\begin{tabular}{|c|c|c|c|c|c|}
\hline & \multicolumn{2}{|c|}{ Mechanism I } & \multicolumn{2}{|c|}{ Mechanism II } & \multirow{2}{*}{ Total } \\
\hline $\begin{array}{l}\text { Cause of death and age } \\
\text { group }\end{array}$ & Cold stress & Heat stress & Cold stress & Heat stress & \\
\hline $\begin{array}{c}\text { Ischemic heart disease, } \\
30-64\end{array}$ & $\begin{array}{c}-2.9^{*} \\
(-4.7 ;-1.2)\end{array}$ & $\begin{array}{c}1.8 \\
(-.29 ; 3.9)\end{array}$ & $\begin{array}{c}-.51^{*} \\
(-.94 ;-.24)\end{array}$ & 0 & $\begin{array}{c}-1.7 \\
(-4.4 ; 1.1)\end{array}$ \\
\hline $\begin{array}{c}\text { Ischemic heart disease, } \\
\geq 65\end{array}$ & $\begin{array}{c}-4.8^{*} \\
(-7.5 ;-2.0)\end{array}$ & $\begin{array}{c}3.3 \\
(-.53 ; 7.1)\end{array}$ & $\begin{array}{c}-.37^{*} \\
(-.72 ;-.17)\end{array}$ & 0 & $\begin{array}{c}-1.8 \\
(-6.6 ; 2.9)\end{array}$ \\
\hline $\begin{array}{c}\text { Cerebrovascular } \\
\text { diseases, } 30-64\end{array}$ & $\begin{array}{c}-3.9^{*} \\
(-6.1 ;-1.6)\end{array}$ & $\begin{array}{c}.77 \\
(-.28 ; 1.8) \\
\end{array}$ & 0 & 0 & $\begin{array}{c}-3.1^{*} \\
(-5.6 ;-.63) \\
\end{array}$ \\
\hline $\begin{array}{l}\text { Cerebrovascular } \\
\text { diseases, } \geq 65\end{array}$ & $\begin{array}{c}-4.7^{*} \\
(-7.5 ;-2.0)\end{array}$ & $\begin{array}{c}1.0 \\
(-.16 ; 2.2) \\
\end{array}$ & $\begin{array}{c}-.42^{*} \\
(-.77 ;-.20) \\
\end{array}$ & $\begin{array}{c}.50^{*} \\
(.00 ; 1.00)\end{array}$ & $\begin{array}{c}-3.6^{*} \\
(-6.7 ;-.60) \\
\end{array}$ \\
\hline $\begin{array}{c}\text { Respiratory diseases, } \\
30-64\end{array}$ & $\begin{array}{c}-3.5^{*} \\
(-5.5 ;-1.5)\end{array}$ & $\begin{array}{c}-.89 \\
(-1.9 ; .14)\end{array}$ & $\begin{array}{c}-.49^{*} \\
(-1.11 ;-.27)\end{array}$ & 0 & $\begin{array}{c}-4.8^{*} \\
(-7.2 ;-2.6)\end{array}$ \\
\hline $\begin{array}{l}\text { Respiratory diseases, } \\
\quad \geq 65\end{array}$ & $\begin{array}{c}-2.6^{*} \\
(-4.1 ;-1.1)\end{array}$ & $\begin{array}{c}-.04 \\
(-.10 ; .01)\end{array}$ & 0 & 0 & $\begin{array}{c}-2.6^{*} \\
(-4.1 ;-1.1)\end{array}$ \\
\hline $\begin{array}{l}\text { All non-accidental } \\
\text { causes, 30-64 }\end{array}$ & $\begin{array}{c}-.73^{*} \\
(-1.3 ;-.15)\end{array}$ & $\begin{array}{c}.44 \\
(-.07 ; .95)\end{array}$ & $\begin{array}{c}-.30^{*} \\
(-.54 ;-.14)\end{array}$ & 0 & $\begin{array}{c}-.59 \\
(-1.4 ; .20)\end{array}$ \\
\hline $\begin{array}{l}\text { All non-accidental } \\
\quad \text { causes, } \geq 65\end{array}$ & $\begin{array}{c}-1.6^{*} \\
(-2.5 ;-.67)\end{array}$ & $\begin{array}{c}.30 \\
(-.05 ; .64)\end{array}$ & $\begin{array}{c}-.41^{*} \\
(-.64 ;-.19)\end{array}$ & $\begin{array}{c}.22^{*} \\
(.00 ; .44)\end{array}$ & $\begin{array}{c}-1.5^{*} \\
(-2.5 ;-.46)\end{array}$ \\
\hline $\begin{array}{c}\text { All external causes, } \\
30-64 \\
\end{array}$ & $\begin{array}{c}-3.6^{*} \\
(-5.7 ;-1.5) \\
\end{array}$ & $\begin{array}{c}1.3 \\
(-.22 ; 2.9) \\
\end{array}$ & $\begin{array}{c}-.54^{*} \\
(-.95 ;-.25) \\
\end{array}$ & 0 & $\begin{array}{c}-2.8^{*} \\
(-5.5 ;-.18) \\
\end{array}$ \\
\hline $\begin{array}{l}\text { All external causes, } \\
\geq 65\end{array}$ & $\begin{array}{c}-2.6^{*} \\
(-4.1 ;-1.1)\end{array}$ & $\begin{array}{c}1.0 \\
(-.16 ; 2.1)\end{array}$ & 0 & 0 & $\begin{array}{c}-1.6 \\
(-3.5 ; .27)\end{array}$ \\
\hline
\end{tabular}

Mechanism I refers to temperature-mortality curves established in all temperature range but the extreme temperatures; Mechanism II refers to temperature waves only; zero values mean that the Null hypothesis could not be rejected.

${ }^{*}$ Significant at $95 \%$ level.

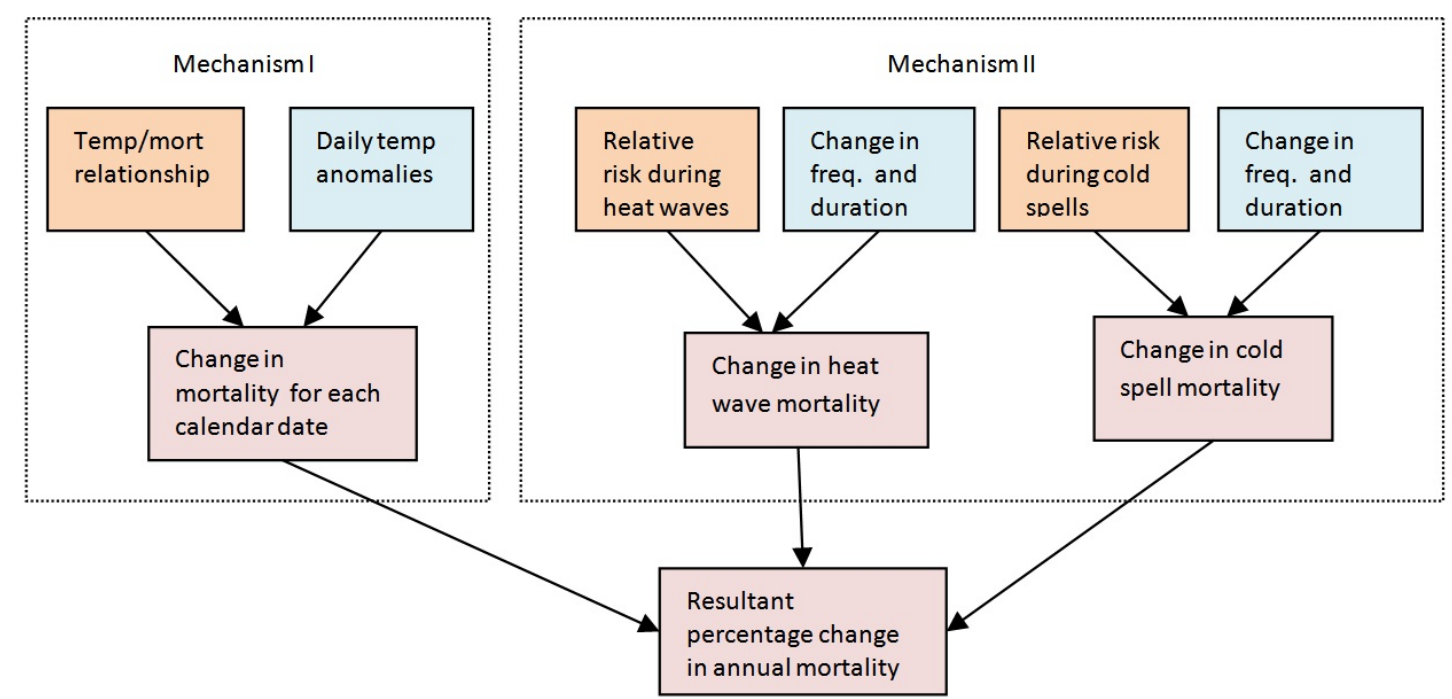

Figure 1. Schematic describing integration of historical mortality and weather data with climate models output to predict climate change-induced mortality 

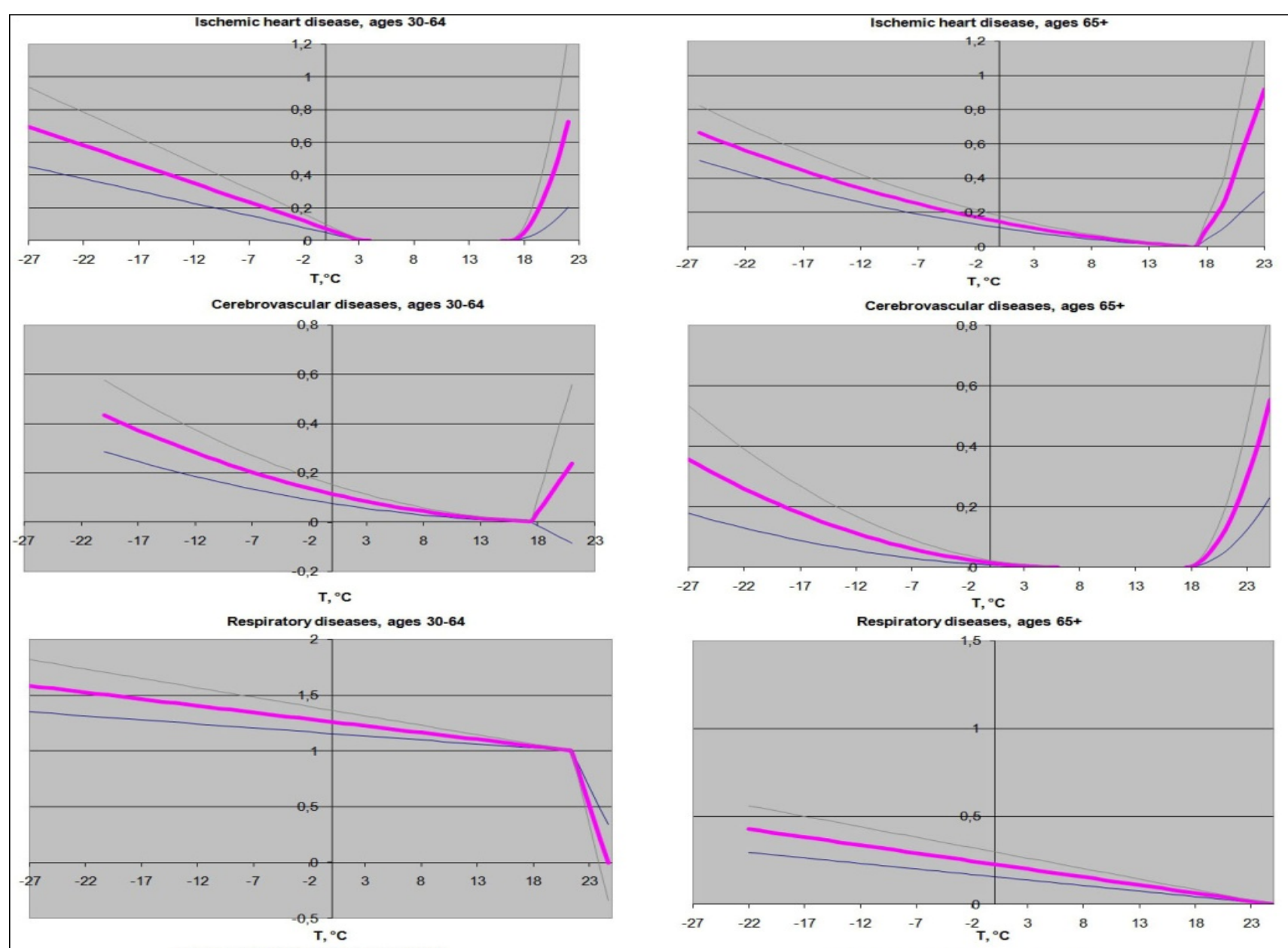

All non-accidental causes, ages 30-64
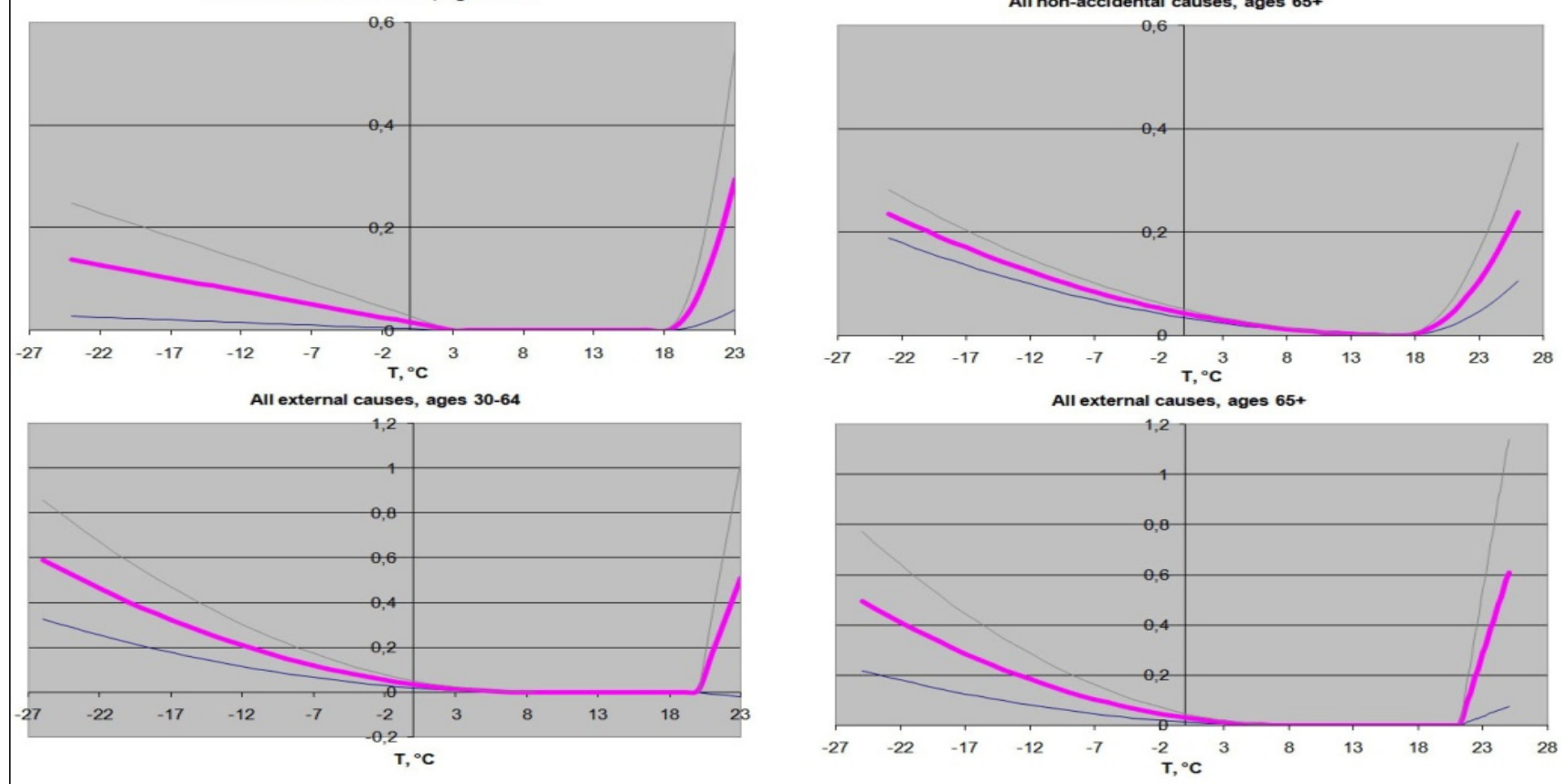

- Lower $95 \% \mathrm{CL} \longrightarrow$ mean - upper $95 \% \mathrm{CL}$

Figure 2. Temperature-mortality curves

Vertical axis shows relative increase in mortality above the point of minimum. 


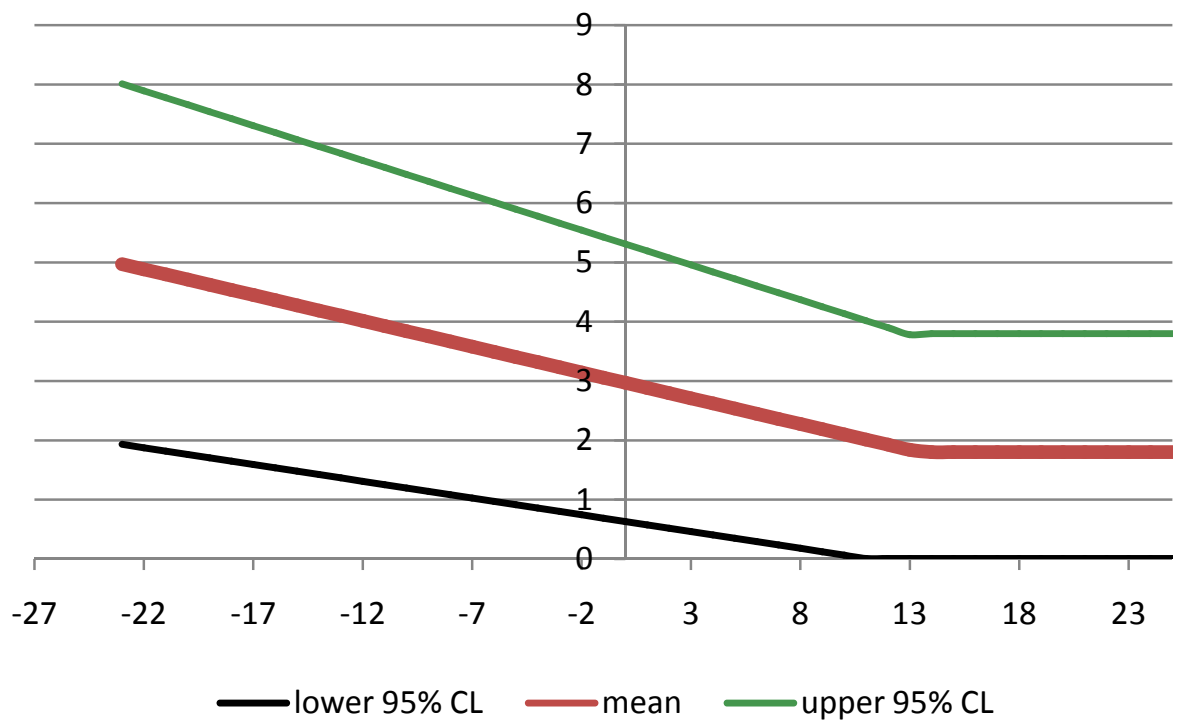

Figure 3. A piecewise approximation of daily temperature anomalies $T_{f}-T_{h}$ in Archangelsk between future period 2041-2060 and baseline period 1980-1999 as a function of historic temperature $T_{h}$. The results were averaged over the ensemble of 9 selected AOGCMs under IPCC A2 greenhouse gas emission scenario.

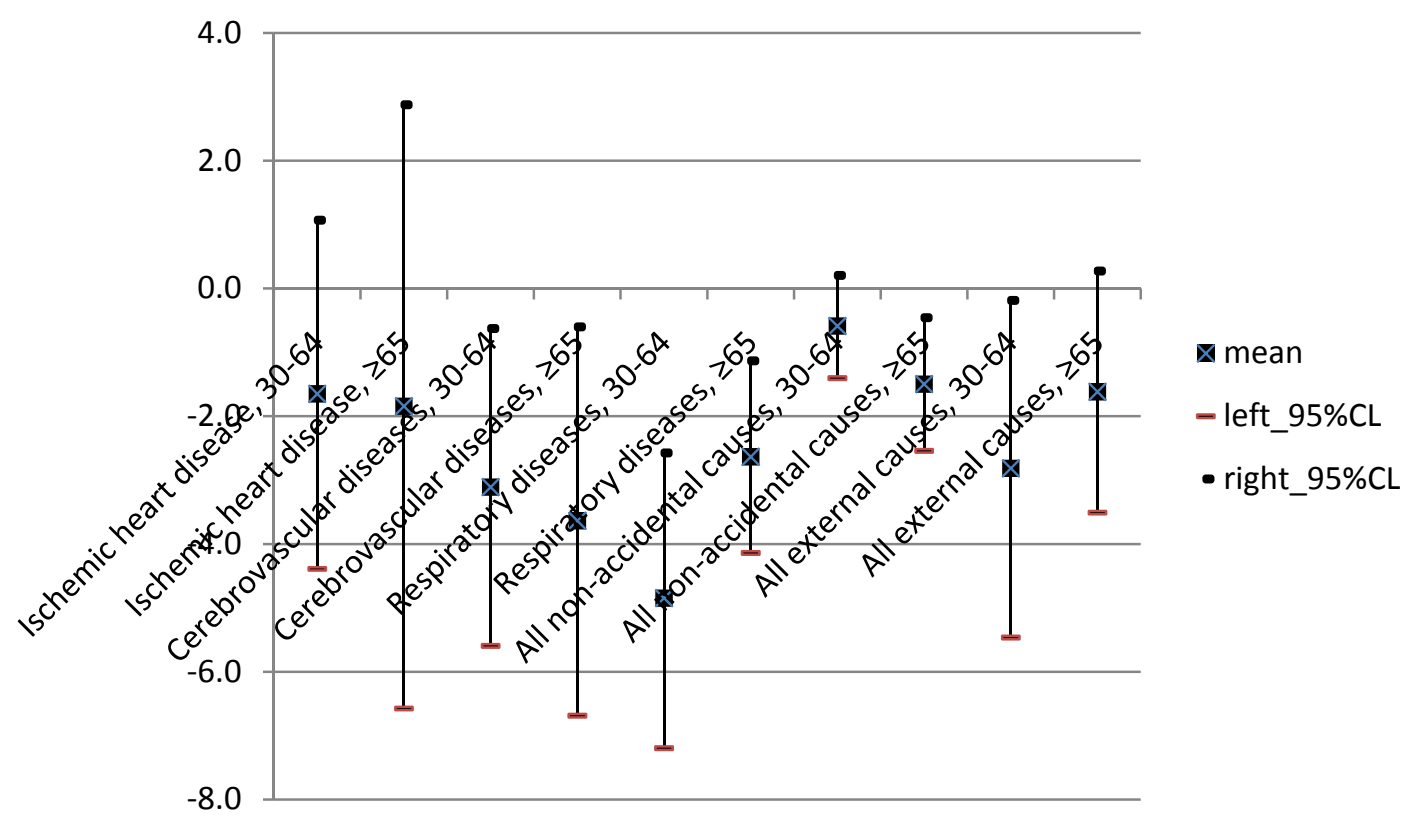

Figure 4. Percentage changes in average annual mortality rates between the future (2041-2060) and the baseline (1980-1999) periods, summed over both mechanisms shown in Figure 1 